\title{
MICROSTRUCTURE AND MECHANICAL PROPERTIES OF TIAI-BASED ALLOY PRODUCED BY SELECTIVE LASER MELTING
}

\author{
${ }^{1}$ Igor POLOZOV, ${ }^{1}$ Artem KANTYUKOV, ${ }^{2}$ Vera POPOVICH, ${ }^{2}$ Jia-Ning ZHU, ${ }^{1}$ Anatoly POPOVICH \\ ${ }_{1}^{1}$ Peter the Great St. Petersburg Polytechnic University, St. Petersburg, Russia, polozovia@spbstu.ru \\ ${ }^{2}$ Delft University of Technology, Department of Materials Science and Engineering, Delft, The Netherlands
}

https://doi.org/10.37904/metal.2020.3604

\begin{abstract}
Additive Manufacturing (AM) is an attractive way of producing parts of intermetallic titanium alloys. However, high brittleness of these alloys makes it challenging to produce crack-free intermetallic parts by AM. One way to overcome this problem is to use high-temperature powder-bed preheating. In this paper, Ti-48Al-2Cr-2Nb alloy was obtained by selective laser melting process with high-temperature preheating of $800-900^{\circ} \mathrm{C}$. Crackfree specimens with a relative density of $99.9 \%$ were fabricated using an optimized process parameter set. Microstructure and phase composition were studied using scanning electron microscopy and X-Ray diffraction to reveal a fine microstructure consisting of lamellar $\alpha 2 / \gamma$ colonies, equiaxed $y$ grains, and retained $\beta$ phase. Compressive tests and microhardness measurements showed that the produced alloy exhibited superior properties compared to the conventionally obtained TiAl-alloy.
\end{abstract}

Keywords: Selective laser melting, additive manufacturing, titanium aluminide, intermetallics

\section{INTRODUCTION}

TiAl-based intermetallic alloys are attractive materials for high-temperature applications due to their high specific strength at room and elevated temperatures, good creep and oxidation resistance [1]. These properties make them promising candidates for replacing nickel-based superalloys in gas turbine engines [2]. One of the most widely known $\mathrm{Y}$-TiAl alloys is the Ti-48Al-2Cr-2Nb (at. \%) alloy. While TiAl alloys possess high strength, their poor ductility and brittleness at room temperatures severely complicate their processability by conventional manufacturing techniques and limit their application [3].

Additive Manufacturing (AM) is a promising way to manufacture intermetallic alloy parts since it offers significant advantages in terms of design freedom and cost reduction compared to conventional methods. However, high cooling rates typical for powder bed AM techniques lead to high residual stresses which makes it difficult to produce crack-free intermetallic parts [4]. The published data indicates that high-temperature preheating is needed to obtain crack-free intermetallic parts [5]. Selective Electron Beam Melting (SEBM) has been proved feasible in fabrication of TiAl alloys [6-8]. Utilizing an electron beam to preheat the powder bed to temperatures around $1000^{\circ} \mathrm{C}$ allows to drastically reduce residual stresses and suppress crack formation during the fabrication of TiAl alloys. One disadvantage of SEBM process is its much lower geometrical precision compared to Selective Laser Melting (SLM) process, also known as laser powder-bed fusion (L-PBF) process. High-temperature powder bed preheating is required to produce crack-free TiAl alloys using the LPBF process. At the moment, studies devoted to the L-PBF process with high-temperature preheating are limited and the subject needs to be investigated.

This paper reports the results of the investigation of L-PBF process using Ti-48Al-2Cr-2Nb alloy powder with an inductive high-temperature platform preheating. The effects of L-PBF process parameters and preheating temperature on fabricated TiAl-alloy microstructure and mechanical properties are investigated. 


\section{MATERIALS AND METHODS}

Gas atomized (GA) spherical powder (as can be seen in Figure 1) with a nominal composition of Ti-48Al-2Cr$2 \mathrm{Nb}$ (at. \%) was used to fabricate the samples. The powder had the following particle size distribution: $d_{10}=$ $17.4 \mu \mathrm{m}, \mathrm{d}_{50}=33.8 \mu \mathrm{m}, \mathrm{d}_{90}=60.5 \mu \mathrm{m}$.

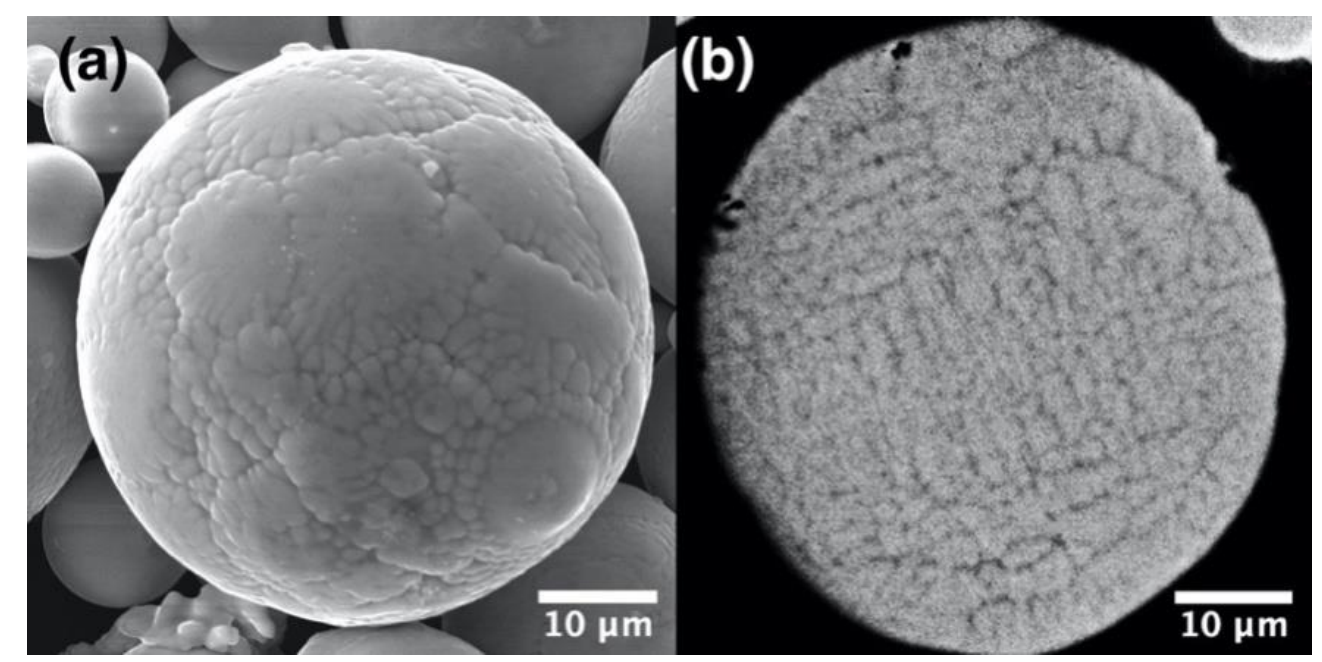

Figure 1 SEM images of the gas atomized powder (GA) showing (a) surface morphology and (b) crosssection of a particle

The L-PBF process was carried out using Aconity MIDI (Aconity3D GmbH, Germany) system equipped with a $1070 \mathrm{~nm}$ wavelength fiber laser with a maximum power of $1000 \mathrm{~W}$. Cylindrical samples with $10 \mathrm{~mm}$ diameter and $10 \mathrm{~mm}$ height were fabricated for further investigation. The samples were fabricated on a Ti-6Al-4V substrate, which was put on a molybdenum platform. The molybdenum substrate was inductively preheated to a set temperature, which was continuously controlled by a thermocouple under the molybdenum platform. The titanium substrate was then conductively heated by the molybdenum substrate before starting the L-PBF process. The process chamber was continuously flooded with high purity argon gas to achieve oxygen content in the chamber below $20 \mathrm{ppm}$. After the build process was finished, the platform and the samples were cooled down to room temperature with a cooling rate of approximately $5^{\circ} \mathrm{C} / \mathrm{min}$. The platform preheating temperature was varied from 600 to $900^{\circ} \mathrm{C}$ and the scanning speed (S) was varied from 650 to $1250 \mathrm{~mm} / \mathrm{s}$, while the laser power $(P)$, hatching distance $(H D)$, and layer thickness $(L)$ were set to a fixed value for most of the samples. As a result of the parameters change, the volume energy density varied from 36 to $70 \mathrm{~J} / \mathrm{mm}^{3}$.

The as-fabricated samples were cut and polished along the build direction (BD) for the microstructural characterization. Mira 3 LMU TESCAN scanning electron microscope (SEM) in backscattered electrons (BSE) mode was utilized to evaluate the microstructures. Energy Dispersive Spectroscopy (EDS) was used for the chemical analysis of the samples and powders on the polished cross-sections. The phase composition of the powders and the fabricated samples was analyzed with a Bruker D8 Advance X-ray diffraction (XRD) using Cu-Ka $(\lambda=0.15418 \mathrm{~nm})$ irradiation.

The relative density was measured by a standard metallographic technique, which includes taking a minimum of five different locations of the polished samples with an optical microscope (OM) Leica DMI5000 (Leica, Germany) at 50x magnification. The OM images were then used to isolate the pores from the bulk material using ImageJ software.

Room temperature compression tests were performed using a universal testing machine (Zwick/Roell Z100, Germany) with a strain rate of $0.1 \mathrm{~mm} / \mathrm{min}$. A minimum of three samples per point were tested. 


\section{RESULTS AND DISCUSSION}

Figure 2 shows the effect of platform preheating temperature on the formation of cracks in samples fabricated from the MAPS powder. As can be seen in Figure 2 (a), severe cracking is observed when a relatively low preheating temperature of $600^{\circ} \mathrm{C}$ was used during the L-PBF process. Increasing the preheating temperature to $800{ }^{\circ} \mathrm{C}$ significantly reduced the number of cracks, however occasional horizontal cracks perpendicular to the build direction were still present. Further increase in the preheating temperature up to $900{ }^{\circ} \mathrm{C}$ resulted in elimination of cracks. This is in agreement with the brittle-ductile transition temperature (BDTT) of the TiAlalloy, which is around $750-780^{\circ} \mathrm{C}$ [9]. Increased ductility above the BDDT allows the material to accommodate high stresses during L-PBF and avoid cracking. Further investigation of the relative density was carried out only on the samples fabricated at 800 and $900{ }^{\circ} \mathrm{C}$ preheating temperatures.

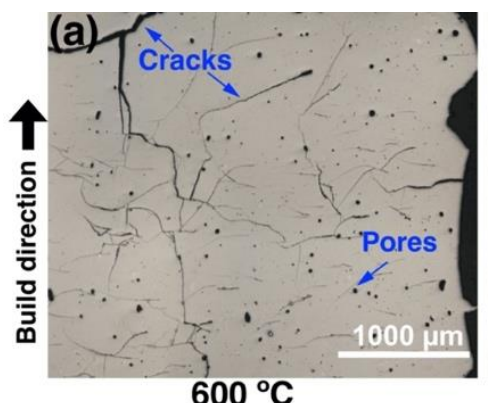

$600{ }^{\circ} \mathrm{C}$

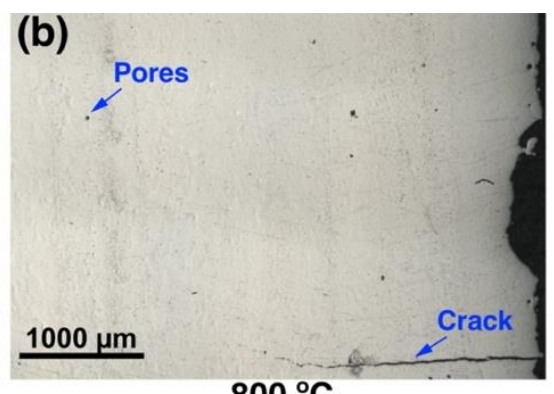

$800{ }^{\circ} \mathrm{C}$

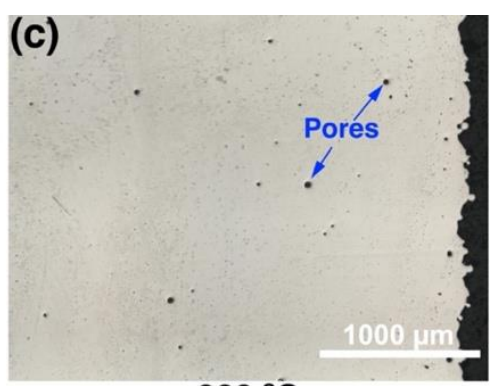

$900^{\circ} \mathrm{C}$

Figure2 Optical images of the cross-sections of the samples fabricated using different preheating temperatures: (a) $600^{\circ} \mathrm{C}$, (b) $800^{\circ} \mathrm{C}$; (c) $900^{\circ} \mathrm{C}$

Figure 3 shows the effect of scanning speed on the relative density of the samples. The highest relative density of $99.94 \pm 0.05 \%$ was obtained at $800{ }^{\circ} \mathrm{C}$ preheating temperature and $950 \mathrm{~mm} / \mathrm{s}$ scanning speed which corresponds to $48 \mathrm{~J} / \mathrm{mm}^{3}$ volume energy density. In general, a higher preheating temperature resulted in a slightly higher porosity, which suggests that some overheating might have taken place during the L-PBF and led to formation of keyhole pores.

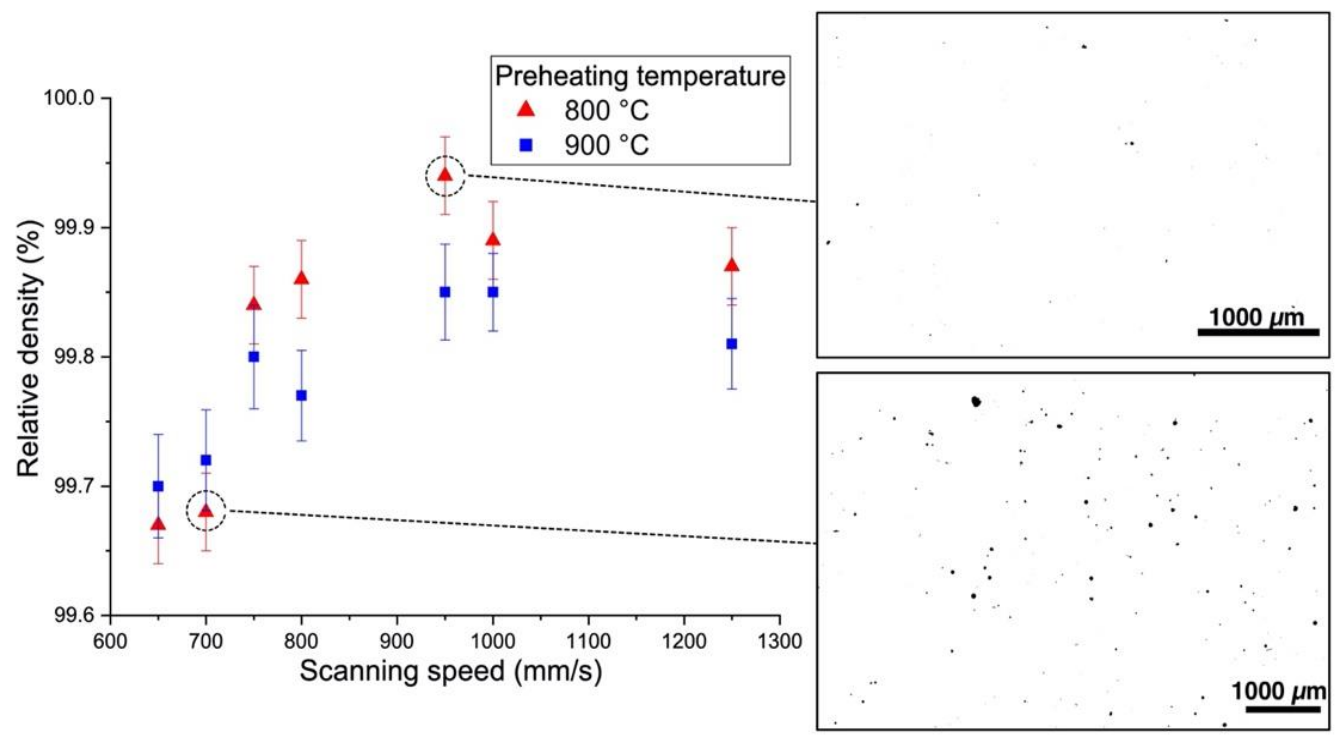

Figure 3 Effect of scanning speed and platform preheating temperature on the relative density of the samples with cross-section images showing typical pore distribution

Figure 4 shows microstructures of the samples fabricated at $800^{\circ} \mathrm{C}$ and $900^{\circ} \mathrm{C}$ preheating temperatures. The obtain microstructure mainly consists of lamellar $\alpha 2 / \gamma$ colonies, equiaxed $\gamma$ grains, and the retained $\beta$ phase. 
Crescent-shaped melt pool boundaries with a width of about 80-90 $\mu \mathrm{m}$ can be found in the microstructure as shown in Figure 4(a). Retained $\beta$-phase was also found in the microstructure of the SEBM-processed Ti-48Al$2 \mathrm{Cr}-2 \mathrm{Nb}$ alloy in the paper [10]. While the Ti-48Al-2Cr-2Nb is an $\alpha$-solidifying alloy, high cooling rates during the L-PBF process can induce solidification of a metastable $\beta$-phase. Moreover, Al loss might also play a role in the microstructure formation. Reducing the Al concentration leads to the solidification through the Ti-rich side of the peritectic reaction and formation of the $\beta$-phase. Retained $\beta$-phase in the TiAl-alloy can increase its ductility, however the strength at room and elevated temperatures can be worsened due to refractory elements segregation and reduced solid solution strengthening in the lamellar regions [11]. Thus, a subsequent heat treatment should be considered to transform metastable $\beta$-phase in the TiAl alloy.
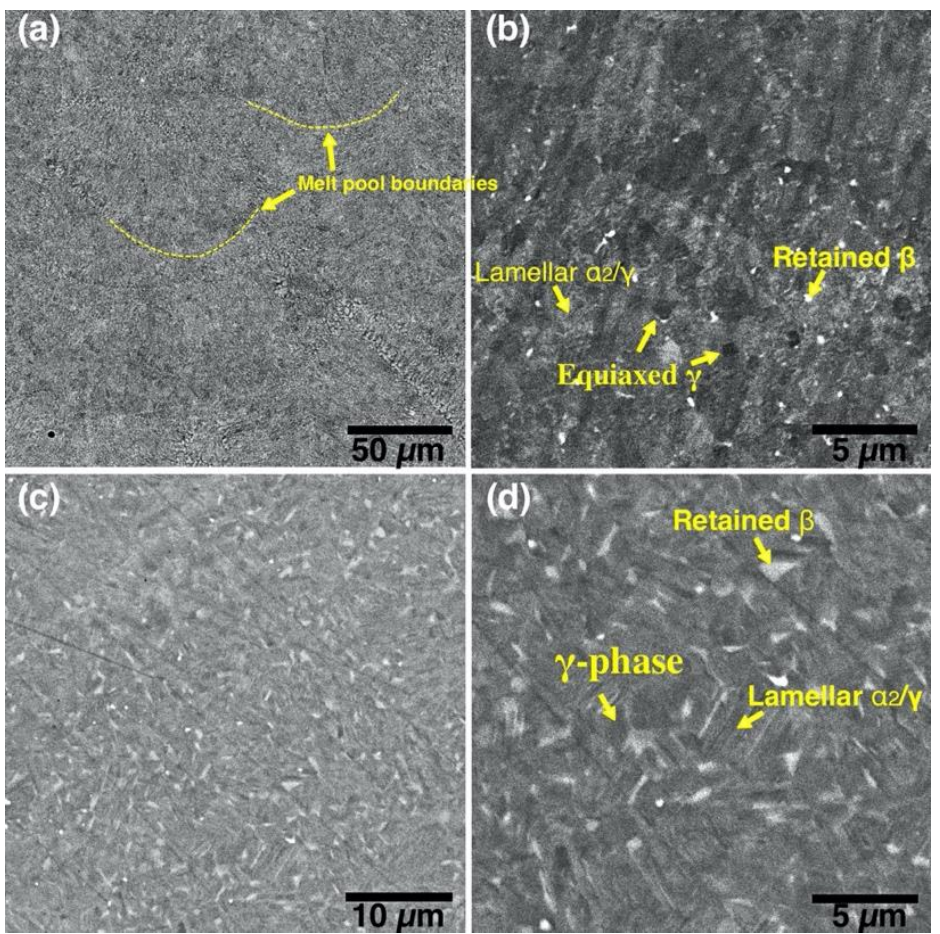

Figure 4 BSE-SEM images showing microstructures of the samples fabricated from GA powder at $(a, b) 800$ ${ }^{\circ} \mathrm{C}$ and (c, d) $900{ }^{\circ} \mathrm{C}$ preheating temperature

Table 1 presents the results of room temperature compressive tests of the samples fabricated at $900{ }^{\circ} \mathrm{C}$ preheating temperature. The samples showed high ultimate compressive strength values of $2277 \pm 71 \mathrm{MPa}$. The compressive strain values were around $32-35 \%$.

Table 1 Comparison of mechanical properties of TiAl alloy manufactured by different processes

\begin{tabular}{|l|l|c|c|}
\hline Material & Condition & UCS (MPa) & Compres. strain (\%) \\
\hline Ti-48Al-2Cr-2Nb (this study) & As-fabricated, $900^{\circ} \mathrm{C}$ preheating & $2277 \pm 71$ & $32-35$ \\
\hline Ti-48Al-2Cr-2Nb (SEBM)[12] & As-fabricated & 1800 & 40 \\
\hline Ti-48Al-2Cr-2Nb (L-PBF) [12] & As-fabricated, no preheating & $612 \pm 56$ & $1.98 \pm 0.55$ \\
\hline Ti-48Al-2Cr-2Nb (SEBM) [13] & Heat-treated & 2068 & 25 \\
\hline Ti-48Al-2Cr-2Nb (casted) [13] & As-fabricated & 1153 & $\sim 6$ \\
\hline
\end{tabular}

The room temperature compressive performance of the samples fabricated by L-PBF with a high-temperature preheating showed promising results and exceeded the compressive strength of SEBM samples and showed significantly better results than the samples fabricated by L-PBF with a non-preheated platform [12]. 


\section{CONCLUSION}

In this paper, it was demonstrated that crack-free TiAl-based alloy samples can be fabricated using the L-PBF process with high-temperature platform preheating. Crack-free samples were fabricated with $900^{\circ} \mathrm{C}$ platform preheating temperature. The highest relative density of $99.9 \%$ was obtained at volume energy density 48 $\mathrm{J} / \mathrm{mm}^{3}$. Fine microstructure consisting of lamellar $\alpha_{2} / \gamma$ colonies, equiaxed $\gamma$ grains, and retained $\beta$ phase was obtained. The fabricated samples showed high ultimate compressive strength and strain values which are superior compared to the conventional TiAl-alloy.

\section{ACKNOWLEDGEMENTS}

This research was supported by Russian Science Foundation grant (project No 19-79-30002).

\section{REFERENCES}

[1] GUYON, J., HAZOTTE, A., WAGNER, F., BOUZY, E. Recrystallization of coherent nanolamellar structures in Ti48Al2Cr2Nb intermetallic alloy. Acta Mater. Jan. 2016, vol. 103, pp. 672-680.

[2] BARTOLOTTA, P., BARRETT, J., KELLY, T., SMASHEY, R. The use of cast Ti-48Al-2Cr-2Nb in jet engines. JOM. May 1997, vol. 49, no. 5, pp. 48-50.

[3] GUPTA, R.K., PANT, B., SINHA, P.P. Theory and practice of $Y+\alpha 2$ Ti aluminide: A review. Trans. Indian Inst. Met. Apr. 2014, vol. 67, no. 2, pp. 143-165.

[4] SHI, X., WANG, H., FENG, W., ZHANG, Y., MA, S., WEI, J. The crack and pore formation mechanism of Ti47Al-2Cr-2Nb alloy fabricated by selective laser melting. Int. J. Refract. Met. Hard Mater. Mar. 2020, p. 105247.

[5] DOUBENSKAIA, M., DOMASHENKOV, A., SMUROV, I., PETROVSKIY, P. Study of Selective laser melting of intermetallic TiAl powder using integral analysis. Int. J. Mach. Tools Manuf. Jun. 2018, vol. 129, pp. 1-14.

[6] BAUDANA, G. et al. Electron beam melting of Ti-48Al-2Nb-0.7Cr-0.3Si: Feasibility investigation. Intermetallics. 2016, vol. 73, pp. 43-49.

[7] MURR, L.E. et al. Characterization of titanium aluminide alloy components fabricated by additive manufacturing using electron beam melting. Acta Mater. Mar. 2010, vol. 58, no. 5, pp. 1887-1894.

[8] BAUDANA, G. et al. Titanium aluminides for aerospace and automotive applications processed by electron beam melting: Contribution of Politecnico di Torino. Met. Powder Rep. 2016, vol. 71, no. 3, pp. 193-199.

[9] CHEN, R. et al. Brittle-ductile transition during creep in nearly and fully lamellar high-Nb TiAl alloys. Intermetallics. Feb. 2018, vol. 93, pp. 47-54.

[10] SCHWERDTFEGER, J., KÖRNER, C. Selective electron beam melting of Ti-48AI-2Nb-2Cr: Microstructure and aluminium loss. Intermetallics. 2014, vol. 49, pp. 29-35

[11] NISHIKIORI, S.,TAKAHASHI, S.,SATOU, S., TANAKA, T. MATSUO, T. Microstructure and creep strength of fullylamellar TiAl alloys containing beta-phase. Mater. Sci. Eng. A. Jun. 2002, vol. 329-331, pp. 802-809.

[12] LOEBER, L. et al. Comparison of selective laser and electron beam melted titanium aluminides. In 22nd Annual International Solid Freeform Fabrication Symposium - An Additive Manufacturing Conference, SFF 2011, 2011.

[13] KIM, Y.-K., HONG, J.K., LEE, K.-A. Enhancing the creep resistance of electron beam melted gamma Ti-48Al2Cr-2Nb alloy by using two-step heat treatment. Intermetallics. Jun. 2020, vol. 121, p. 106771. 